\title{
A atualidade \\ de T. H. Marshall no estudo da cidadania no Brasil
}

Lea Guimarães Souki*

\section{Introdução}

O tema da cidadania já é bastante estudado no Brasil, no entanto, em muitas circunstâncias, não é abordado com a devida clareza, na medida em que o conceito mescla-se com a atividade política. $\mathrm{O}$ que aqui se pretende enfatizar são pressupostos que, sob o meu ponto de vista, estão contidos no trabalho de T. H. Marshall e que poderiam ser objeto de debate no estudo da cidadania no Brasil. Trata-se, especialmente, de explorar uma possível presença de uma espécie de rationale das classes dominantes em relação à tolerância acerca da desigualdade no caso inglês. Haveria implícito no trabalho de Marshall o esboço de um projeto de nação das classes dominantes inglesas em relação à quantidade de desigualdade compatível com o que concebem como vida civilizada?

O trajeto a ser seguido na argumentação é o seguinte. Em primeiro lugar, um esclarecimento sobre os conteúdos, empíricos e normativos que delineiam o conceito de cidadania no Brasil. Em segundo lugar, a consideração de um dos

* Doutora em Sociologia Política pela UnB, professora titular no PPG em Ciências Sociais na PUC-MG; áreas de pesquisa: cidadania, metrópole. Mail: leaguim@terra.com.br.

\begin{tabular}{|l|l|l|l|l|l|} 
Civitas & Porto Alegre & v. 6 & n. 1 & jan.-jun. 2006 & p. 39-58 \\
\hline
\end{tabular}


aspectos teóricos mais relevantes considerados por T. H. Marshall, a saber, a tensão existente no próprio conceito entre os princípios de direitos iguais e a desigualdade contida na ordem capitalista. Finalmente, coloca-se a questão se se pode inferir, no caso do Brasil, a inexistência, do ponto de vista das classes dominantes, de um cálculo ou até mesmo de uma preocupação sobre o quanto de desigualdade seria tolerável como parte da construção da nação.

\section{O conceito e a atividade política}

Para realçar os aspectos que considero relevantes, inicio a discussão procurando esclarecer o que o conceito não é. Como já foi afirmado anteriormente, o conceito se confunde com a atividade política. $\mathrm{O}$ primeiro ponto a chamar a atenção é sua reificação como se a cidadania tivesse corpo visível e material e fosse, ao mesmo tempo, capaz de ter vida própria (Carvalho, 1998). Afirmações como, por exemplo, "a cidadania reagiu favoravelmente a tal candidatura ou deixe a cidadania chegar ao seu bairro, a cidadania não tolerará tal coisa" e dezenas de outras formulações similares revelam um conceito carregado de conteúdos e projeções. Esta espécie de ficção, do ponto de vista teórico, traz alguma obscuridade ao conceito e o impregna de senso comum e estereotipia que, embora seja compatível com a atividade política, não favorece a sua precisão conceitual nem tampouco a sua compreensão.

O segundo ponto é o de que cidadania não é sinônimo de democracia, pois, embora guardem nexos estreitos entre si, esses dois conceitos revelam amplitudes diferentes. Tomando apenas o contexto da transição à democracia no Brasil, podendo também ser incluídos outros países da América Latina nos anos de 1980 e da Europa Meridional nos anos de 1970, o discurso político do início desse período esteve impregnado da idéia de cidadania. As oposições à ditadura tomaram este discurso para afirmar direitos antes interditados, assim como para se diferenciar dos setores de oposição que teriam adotado a confrontação armada no período anterior. A idéia de luta pela conquista da cidadania procurava afirmar, dentro da legalidade institucional, tudo o que se teria direito como país civilizado sem colocar em xeque a ordem estabelecida. Nesse contexto, ela também continha a bandeira da defesa de direitos, bem como a idéia de civilidade, enquanto cumprimento das obrigações do Estado e dos indivíduos. 
Um terceiro conteúdo confundido com cidadania situa-se historicamente no momento seguinte à transição democrática, quando cidadania passou a ser sinônimo de empowerment. Este conteúdo de empoderamento e fortalecimento da sociedade civil coincidia com as novas experiências da esquerda à frente de funções executivas no plano local, contando com a adesão dos setores da sociedade civil potencialmente participativos. Estes setores ativos da sociedade, participantes das políticas públicas como objeto e, às vezes, como sujeito, reivindicam, além de serviços, também bens simbólicos. Nesse sentido, pode-se dizer que as exigências de provisão fazem parte do processo de cidadania, mas não o esgotam.

Em quarto lugar, seria importante lembrar que a idéia de participação, incluindo a virtude cívica da maneira como a entende Tocqueville, tampouco seria capaz de abarcar todo o conteúdo do conceito, embora seja dele uma parte integrante. Uma definição mais completa incluiria além da noção de participação, as dimensões de titularidade de direitos e a de pertencimento a uma comunidade cívica, ambas contempladas no estudo de Marshall (Carvalho, 1998).

A cidadania é fundamentalmente um método de inclusão social. Historicamente ela representou o surgimento e a celebração do indivíduo enquanto unidade política desvinculado das instituições gremiais e corporativas, cujo início se deu no contexto das revoluções inglesas do século XVII, na Revolução Francesa e no Bill of Rights, alguns anos antes. A inspiração comum a todas essas tradições está nos direitos naturais que, enquanto naturais, eram anteriores à instituição do poder civil e, por isso, deveriam ser reconhecidos e protegidos por este poder.

\section{A tensão permanente no conceito}

\section{O caso inglês}

Como expôs Bendix (1996), a experiência inglesa do desenvolvimento da cidadania é a exceção e não a regra. O desenvolvimento da industrialização, concomitante com o da democracia, só se deu, da maneira como descreve Marshall, na Inglaterra. Nos Estados Unidos, por exemplo, a mobilização popular ocorreu antes da industrialização. Em diversos países do sul e do leste da Europa, os direitos sociais foram adquiridos sob regimes políticos autoritários e focados apenas em uma parte da sociedade. Isto é, esses direitos visavam a 
atingir algum setor específico da classe trabalhadora, em meio a um jogo de alianças, cooptações e reconhecimento de novos atores, sem nenhum conteúdo universalista. No espectro dos países europeus, os casos mais próximos do modelo inglês encontram-se em alguns países escandinavos.

Teoricamente, a referência básica no estudo da cidadania é T. H. Marshall (1967) que, estudando o caso inglês, cunhou o conceito associando-o ao desenrolar da conhecida seqüência histórica no desenvolvimento dos direitos, cuja ênfase estaria não só na titularidade de direitos, mas também faz alusão ao pertencimento a uma comunidade cívica, embora essa última noção tenha sido mais desenvolvida por Bendix (1996). O primeiro autor, quando lido linearmente, tem dado margem a interpretações apressadas como uma espécie de prescrição do caso inglês como caminho obrigatório. Um dos seus críticos, Mann (1987), chama a atenção sobre o conteúdo etnocêntrico de sua interpretação, ademais, entende-o como portador de uma visão evolucionista da história inglesa, o que o torna incapaz de captar o aspecto conflituoso do desenvolvimento da cidadania e tampouco a estratégia das classes dominantes, ponto de vista contestado por Turner (1992). Para Bottomore (1998), à medida que os anos passam, as referências a Marshall multiplicam-se. Na mesma direção, realçando seu conteúdo de obra clássica, no prefácio ao artigo acima citado, Robert Moore enfatiza que "a profusão de análises e notas de pé de páginas relativas à sua obra (T. H. Marshall) durante as duas últimas décadas oferece provas da influência que ele vem exercendo" (Bottomore, 1998, p. 9). Passados mais de cinqüenta anos de sua publicação ainda existem aspectos que mereceriam ser explorados.

O ponto de vista aqui desenvolvido é de que, embora se tratando de um caso empírico específico, o modelo de Marshall é um recurso teórico importante e continua sendo referência para os estudos comparativos do desenvolvimento da cidadania em outros países. Concordo com Turner (1992), segundo o qual a melhor maneira de estudar esse tema é comparativamente. Para o esclarecimento desta abordagem serão tecidas algumas considerações sobre os atributos e as vantagens do método comparativo na política. De acordo com Sartori (1977), a função da comparação não é simplesmente comparar, mas sobretudo explicar. Através de critérios explícitos, pode-se comparar processos históricos, países, regiões, sistemas partidários, modelos políticos, através de suas semelhanças e, especialmente, de suas diferenças, que passam a ser um recurso heurístico para entender e explicar as particularidades de cada caso, sob uma base conceitual comum. 
Retomando o caso inglês, a cidadania é nacional por definição, para Marshall. O seu desenvolvimento implicou um duplo processo de fusão e separação (grifo meu). A fusão foi geográfica, no sentido de fazer convergir os direitos universais no mesmo território, no caso, o estado-nação. A especialização foi funcional, de maneira que, quando os três elementos da cidadania (civil, político e social) se separaram, cada um tomou seu caminho seguindo seu próprio ritmo. Segundo as palavras de Marshall, o processo de separação teria sido bastante amplo e complexo:

Quando se separaram, os três elementos da cidadania romperam, por assim dizer, toda relação. Tão completo foi o divórcio que, sem violentar demasiadamente a precisão histórica, podemos designar o período formativo de cada um a um século distinto - os direitos civis, no século XVIII; os políticos, no XIX; e os sociais no século XX. Como é natural, estes períodos deverão ser tratados com uma razoável elasticidade, e há certo solapamento evidente, sobretudo entre os dois últimos (Marshall, 1967, p. 65).

A rigor, no caso inglês, o processo de fusão começou no século XII, quando a justiça real adquiriu o poder de definir e defender os direitos civis dos indivíduos. Começa, então, o desgaste dos costumes locais em benefício do direito comum do país. Os tribunais eram instituições de caráter nacional, tendência que se configuraria com mais ênfase no século XVIII. Quanto aos direitos políticos, o Parlamento passou a concentrar em si os poderes políticos da nação; a burocracia, que dava acesso às instituições políticas, reconfigurou-se especificamente no que diz respeito às regras do sufrágio e aos critérios para definir quem poderia ser membro do parlamento. Quanto aos direitos sociais,

[...] as mudanças econômicas os separaram, ao longo do tempo, do seu pertencimento à comunidade da aldeia, da cidade e do grêmio, até que só ficou a Poor Law, que ainda que continuasse sob a administração local, era uma instituição especializada que adquiriu um fundamento nacional (Marshall, 1967, p. 65).

Segundo as palavras do próprio Marshall, "quando a liberdade se fez universal, a cidadania passou de instituição local à instituição nacional” (Marshall, 1967, p. 69). Enfim, os direitos, ao mesmo tempo em que se especializavam e fortaleciam as instituições específicas de cada dimensão da cidadania (os tribunais civis, o parlamento e o executivo em consonância com as políticas sociais), convergiam para a unificação, conforme o princípio do fortalecimento da nação. Esta proporcionava um efeito integrador novo, um sentimento de lealdade a uma civilização que, no entender de Marshall, é sentida como patrimônio comum (Marshall, 1967, p. 84). 


\section{Compatibilidade entre cidadania e desigualdade}

Para o que proponho aqui, devo ressaltar alguns aspectos importantes no texto de T. H. Marshall, no que se refere ao caso inglês. É provável que estes estejam colocados como pressupostos para o autor. Contudo, sua pertinência e seu valor heurístico são um convite a sua exploração, na medida em que sugerem a formulação de uma questão atual acerca da desigualdade no Brasil.

Primeiro, a existência de uma possível rationale das classes dominantes no que diz respeito à tolerância à desigualdade. Não se trata de discutir a estratégia dessas classes como faz Michael Mann (1987), para quem haveria cinco estratégias possíveis no desenvolvimento da cidadania e o caso inglês representaria, em um momento inicial, o principal exemplo da estratégia liberal transitando para uma estratégia reformista no momento seguinte. Considerando que a questão das elites inglesas em relação à desigualdade iria além das estratégias das classes dominantes para lidar com a burguesia e a classe trabalhadora no momento da industrialização não se pretende descartar as motivações de outra natureza. Não se sabe precisamente se uma certa intolerância com a desigualdade se daria por motivos sanitários, estéticos, demográficos ou humanistas. Seja como for, os ingleses já haviam refletido sob vários ângulos e de diversas maneiras sobre a questão da pobreza. Interessase sobretudo discutir algumas idéias contidas, talvez como pressupostos, na reflexão de Marshall. ${ }^{1}$

Na Inglaterra a partir do século XVIII e, especialmente, do XIX, seja do ponto de vista dos Tory, seja dos socialistas, a única referência comum no debate público era a situação do pobre como pedra de toque de uma idéia de civilização, de nação. A discussão pública em torno do tema na Inglaterra não só é muito antiga, como também muito complexa. Pois é composta de uma espécie de substância híbrida, uma mescla que inclui tanto a história social como a história intelectual do período. Sua complexidade aparece, ainda, na variedade de suas fontes, aqui resumidamente situadas como econômica, política, sociológica e literária. É assim que, utilizando somente as fontes públicas do debate, a idéia de pobreza foi tratada na obra de Himmelfarb

1 Para efeito de comunicação, T. H. Marshall será mencionado também como Marshall e quando se tratar de seu predecessor com o mesmo sobrenome será mencionado como Alfred Marshall ou A. Marshall. 
(1981). Segundo esta mesma fonte, no final da era vitoriana, a questão já havia sido esclarecida do ponto de vista teórico e moral, especialmente com a obra de Alfred Marshall e a distinção filosófica entre pobreza e indigência.

Segundo, haveria na classe dominante inglesa uma certa compreensão da interdependência da sociedade e de seu bem-estar que, no citado trabalho de T. H. Marshall, se refletiria em sua afirmação: “[...] a cidadania de que se quer tratar aqui é nacional por definição" (Marshall, 1967, p. 64). Seu desenvolvimento teria implicado duplo processo de fusão e de separação; como já foi mencionado, a fusão foi geográfica e a separação foi funcional. Por exemplo, no século XVII os tribunais locais que defendiam os direitos civis passaram a fazê-lo de acordo o direito comum do país. Na esteira do desenvolvimento dos direitos e no processo de sua ampliação a novos setores da sociedade, antes excluídos, também se fortalecia o sentimento de pertencimento a uma nação. $\mathrm{O}$ caráter universalista desses direitos e o fortalecimento de uma burocracia eficiente configurou um percurso de formação do estadonação diferente das trajetórias de outros países europeus notadamente do leste e do sul. A afirmação de Bendix (1996) segundo a qual Inglaterra não precisou do nacionalismo para o auto-respeito sugere algumas considerações sobre a especificidade da trajetória inglesa, isto sem perder de vista seu caráter exclusivamente insular, o qual exclui o Commonwealth.

Haveria distintas trajetórias no espectro da formação do estado-nação europeu que, do ponto de vista da tese weberiana, foi uma experiência original do ocidente permitindo a resolução, de uma só vez, de dois problemas: o estabelecimento de um modo democrático de legitimação e a base de uma forma nova e abstrata de integração social. No que se refere ao autoentendimento nacional, sobre o qual se referiu no parágrafo anterior, para Habermas, na trajetória européia, esta noção contém um significado ambíguo, levando-se em consideração as contingências históricas nas quais o seu significado foi forjado naquele continente. De um lado, a idéia refere-se "à nação voluntária dos cidadãos, que proporcionam legitimação democrática; por outro, a nação herdada ou atribuída por nascidos nela, facilitando a integração social" (Habermas, 1995, p. 94). No primeiro percurso, prevaleceu o universalismo de uma comunidade legal igualitária e, no segundo, o particularismo de uma comunidade cultural a que se pertence por origem e destino, na qual os ingredientes de sangue e solo ajudaram a formar a lealdade à nação e à unidade territorial. De acordo com o referido autor, a sorte da democracia na 
formação do estado-nação dependeria de como se resolveria a questão do auto-entendimento nacional, isto é, de qual desses dois aspectos dominaria o outro.

Na Inglaterra, o segundo percurso, o do auto-entendimento herdado quase naturalmente, deu lugar à força integradora da cidadania democrática. O que de acordo com a explicação habermasiana, embora não se refira especificamente à Inglaterra, corresponderia à primeira trajetória, conforme a qual "somente a partir de uma representação não-naturalista é que a nação poderá ser combinada harmonicamente com o auto-entendimento universalista do estado constitucional" (Habermas, 1995, p. 94).

As considerações sobre a trajetória inglesa em relação à formação do estado-nação, a existência de uma burocracia eficiente e o progressivo estabelecimento dos direitos e deveres dos cidadãos (melhor dito: súditos) nos permite inferir cautelosamente que havia uma certa lucidez por parte das elites a respeito da interdependência entre os diversos setores da sociedade. Seja esta interdependência baseada no avanço da divisão do trabalho, seja na consciência da necessidade da convivência pacífica necessária à realização do projeto de nação. Não há referências históricas sobre a existência de um descuido em relação à integração da sociedade; ao contrário, os trabalhos de Marshall e Himmelfarb apontam para a existência de elites atentas e, em alguma medida, dialogando publicamente com os reformistas, os intelectuais e os ativistas.

A idéia da consciência de interdependência por parte das elites aqui utilizada tem como referência o trabalho de Elisa Reis, segundo o qual a idéia revelaria o conhecimento da relevância dos problemas sociais, como observa ao abordar o assunto: “[...] consciência da interdependência entre os diferentes setores sociais, elemento que foi crucial na emergência de soluções coletivas e públicas para o problema da pobreza na Europa e que levou, posteriormente, à consolidação do welfare state" (Reis, 2000, p. 148).

\section{A pergunta de Marshall}

Enfim, o aspecto a ser considerado na contribuição de Marshall é, sobretudo, de natureza teórica. Ao discutir, ao longo de seu conhecido terceiro capítulo, Cidadania e classes sociais a compatibilidade entre o desenvolvimento da cidadania na Inglaterra e a existência das desigualdades próprias ao sistema 
capitalista, Marshall formula uma questão que poderia ser considerada crucial na teoria da cidadania. Trata-se da existência de uma tensão permanente entre duas forças opostas e coexistentes: direitos iguais em uma ordem desigual. Esta é uma referência importante sobre a qual proponho estudar o problema.

Implicitamente pode-se ver que a pergunta feita por Marshall seria: qual o grau de desigualdade compatível com os princípios da cidadania? Seu estudo parte de uma pergunta presente no trabalho de seu antecessor, Alfred Marshall. Isto é, ainda tem valor "a hipótese sociológica latente de Alfred Marshall de que existiria uma igualdade humana básica associada ao pertencimento pleno a uma comunidade que não entra em contradição com uma estrutura de desigualdade econômica?" (Marshall, 1967, p. 109). O que permitiu que os dois princípios se reconciliassem e chegassem a ser, ao menos durante um determinado período, aliados? Em sua conferência proferida em Cambridge, em 1949, Marshall se pergunta se ainda seriam válidas as questões formuladas por seu precursor Alfred Marshall em 1873.

T. H. Marshall recoloca a questão da seguinte maneira: ainda seria verdade a idéia de que a igualdade básica do ser humano, quando enriquecida em substância concreta dos direitos formais da cidadania, é consistente com as desigualdades das classes sociais? A igualdade básica seria ainda compatível com o mercado competitivo? Há limites além dos quais o progresso das classes trabalhadoras não poderia ir?

\section{A influência de Alfred Marshall}

À época do trabalho de T. H. Marshall, na Inglaterra não era recente a preocupação explícita com a pobreza no debate público. $\mathrm{Na}$ verdade, ela começou no século XVIII e no século XIX foi marcada por um intenso debate, seja por parte das elites seja por parte dos reformistas oriundos das classes médias. A obra de Alfred Marshall situa-se no final do século XIX no contexto do período vitoriano, período em que o debate se situava na esteira da idéia de moralidade. Esse era o pano de fundo na discussão dos problemas sociais e econômicos e deve-se esclarecer que, naquele momento, não pesava o mesmo sentido de conservadorismo utilizado hoje, pois na Inglaterra esta era a linguagem dos radicais, dos liberais e dos conservadores. Como a era vitoriana cobre um tempo longo com diferentes situações econômicas, políticas e 
sociais, os valores, conhecidos como vitorianos, também se transformaram durante o período. Assim faz-se necessário considerar os três momentos early, high e late, a fim de situar Alfred Marshall no último. Embora tendo formação em matemática, A. Marshall suspeitava das evidências proporcionadas pelas estatísticas divorciadas de valores e via na economia um campo de conhecimento no qual se aplicava a ética cotidiana. A preocupação ética teria levado A. Marshall à Economia, e a Economia o levava ao estudo da pobreza, como observa Himmelfarb,

Political Economy or Economics is a study of mankind in the ordinary business of life; It examines that part of individual and social action which is most closely connected with the attainment and with the use of material requisites of wellbeing. Thus it is on the one side a study of wealth; and on the other, and more important side, a part of the study of man (Himmelfarb, 1991, p. 284-285).

O pressuposto dos vitorianos tardios era que a compaixão seria um sentimento desmesurado e pouco prático. Nessa perspectiva, o sofrimento de uma criança é capaz de nos encher o coração de compaixão, enquanto a notícia de uma batalha com centenas de morte nos é indiferente. Diante disso, os vitorianos-tardios- filantropos, reformistas e críticos da sociedade colocaramse a tarefa de dar a tal sentimento um senso de proporção. Assim Himmelfarb descreve o contexto da discussão:

Theirs was a religious zeal derived from a rigorous theological creed. A later generation of reformers, with a much attenuated commitment to religion, redoubled their social zeal as if to compensate for the loss of religious faith. It was then that compassion for religions was transmuted into the compassion for humanity (Himmelfarb, 1991, p. 4).

Para os vitorianos tardios, a compaixão agora não significaria simplesmente mais um sentimento de puro altruísmo, ela passaria a ter uma implicação prática e até mesmo científica no sentido de ter um tratamento sujeito a cálculos aritméticos. ${ }^{2}$ Ter compaixão significaria tê-la de maneira apropriadamente compreendida, sem a aspiração de ser santo ou mártir. A idéia era melhorar as condições de vida dos pobres, tarefa que lhes parecia possível.

22 Em seu survey, Charles Booth, estudioso da pobreza em Londres no período, insiste sobre a importância da classificação dos níveis de pobreza através do cálculo do que ele chama de arithmetic of woe, aqui traduzido livremente como aritmética do sofrimento (Himmelfarb, 1991, p. 5). 
Feitos os cálculos, dado o senso de proporção, o mal a ser combatido na visão de A. Marshall não seria a pobreza, mas a indigência, degradante e incompatível com a condição humana. Esta desapareceria na medida em que se eliminasse o trabalho excessivo que tornava os homens brutalizados como máquinas. Sua preocupação em nenhum momento era com a desigualdade, mas sim com a brutalização do homem pelo trabalho degradante que o tornava incapaz de pensar e ter sentimento de um cavalheiro, possível a todo e qualquer ser humano.

The question is not whether all men will ultimately be equal -that they certainly will not- but whether progress may go on steadily if slowly, till the official distinction between working man and gentleman has passed away; till, by occupation at least, every man is a gentleman. [...] workers would be gentlemen, and gentlemen would be chivalrous (Himmelfarb, 1991, p. 293).

Para A. Marshall, a verdadeira distinção do homem que trabalha, em contraste com o nobre, não seria o fato de trabalhar, nem o fato de trabalhar com as mãos, tampouco o fato de ser assalariado ou de estar sujeito à disciplina superior. O que o distinguiria seria o efeito do trabalho sobre ele. Portanto, sua preocupação era com a brutalização do homem, ele acreditava que em uma sociedade avançada todo homem poderia ser um cavalheiro.

As idéias de A. Marshall, fundamentadas em suas pesquisas empíricas, apontavam para uma correlação positiva entre o desenvolvimento da divisão do trabalho e o desenvolvimento do estilo de vida dos trabalhadores na Inglaterra. Daí o autor poder afirmar que quando os homens se percebem como homens e não como máquinas de produzir, convertem-se em cavalheiros, condição na qual aceitam progressivamente os deveres públicos e privados do cidadão. A nova economia de Alfred Marshall foi criada neste contexto. Ela procurava reconciliar o ser cavalheiro com o livre mercado. Além disso, suas idéias de Economics of chivalry não evocavam nenhuma exortação ao heroísmo, já que as virtudes do cidadão seriam bastante corriqueiras e se resumiam na disciplina e na dedicação para com os menos afortunados. Sob esta ótica, a cidadania não eliminaria a pobreza, mas a mitigaria. A sociedade civil ideal seria vista como aquela em que o conceito de cidadania transcenderia o conceito de classe. 
As idéias de T. H. Marshall

Desde que foi feita a distinção entre pobreza e indigência, o problema da desigualdade passou a ser tolerado na medida em que não submetesse o homem a uma situação em que estivesse impedido de ser cavalheiro, na qual perdesse a condição de compreender as idéias de dever e de direito - compreensão necessária para a convivência no mesmo espaço. Esse seria o denominador comum que permitiria que pessoas de mundos diferentes pudessem conviver. A impossibilidade da igualdade entre os homens não significava, entretanto, a impossibilidade de que os mesmos se constituíssem em $c a$ valheiros. Segundo A. Marshall, o constituir-se cavalheiro dependia da redução considerável do volume de trabalho pesado e excessivo que brutalizava a classe trabalhadora, e isto só ocorreria através do desenvolvimento da tecnologia. $\mathrm{O}$ formulador dessas idéias não queria ser confundindo com os socialistas, pois era acima de tudo defensor de um mercado livre e sem interferências do Estado.

Quanto à compreensão da classe dominante inglesa em relação à interdependência da sociedade, as idéias de A. Marshall parecem refletir esse entendimento. Como seria conviver no mesmo território com pessoas brutalizadas com as quais necessariamente se terá que manter algum contato? Considerando todo o contexto inglês e as várias fontes de reflexão já mencionadas, a questão que se coloca não é a tolerância com a desigualdade, mas com a pobreza brutalizada?

T. H. Marshall, por sua vez, substitui cavalheiro por civilizado, reinterpreta a idéia de igualdade humana básica, latente no trabalho de A. Marshall, como cidadania, associando-a ao pertencimento pleno a uma comunidade cívica (Marshall, 1967). A partir dessa formulação, o autor depreende que esse pertencimento não entraria em contradição com as desigualdades próprias de uma economia de mercado. Segundo ele, "a desigualdade do sistema de classes seria aceitável sempre que fosse reconhecida a igualdade da cidadania" (Marshall, 1967, p. 94).

Contudo, de acordo com o autor, a cidadania provocou efeitos escassos sobre a desigualdade social até o séc. XIX e os direitos sociais ainda não haviam sido incorporados ao edifício da cidadania. O esforço que havia sido feito não era o de eliminar a pobreza, mas sim seus efeitos desagradáveis. Em 
fins do século XIX tal situação já estava em mudança devido a diversos fatores. A redução das diferenças adquiriu um novo significado com a formação de um mercado consumidor de caráter nacional, sob o qual se desenvolveu a situação que propiciava o desenvolvimento da cidadania de maneira que, "a integração social se estendeu da esfera do sentimento e do patriotismo ao do desfrute material. Os componentes de uma vida culta e civilizada, antes monopólios de alguns, paulatinamente se colocaram à disposição das massas" (Marshall, 1967, p. 88).

Já não se tratava só de acabar com a miséria obviamente desagradável dos estratos mais baixos da sociedade, mas de transformar o modelo geral de desigualdade. Nos termos de Marshall,

o que importa é que se produza um enriquecimento geral do conteúdo concreto da vida civilizada, uma redução generalizada do risco e da insegurança, uma igualação em todos os níveis entre o menos e os mais afortunados. [...] A igualação não se produz tanto entre as classes como entre os indivíduos dentro de uma população que, por isto, já consideramos uma classe A igualdade de status é mais importante que a igualdade de rendas (Marshall, 1967, p. 95, grifo da autora).

Esta é a base sobre a qual Marshall propõe discutir o problema. Quarenta anos depois desse conhecido trabalho, Bottomore reacende o debate com questões que, em certa medida, haviam sido formuladas por Mann (1987). Segundo estes dois autores a preocupação de Marshall se referiria ao impacto do desenvolvimento da cidadania sobre as classes sociais, mas, em nenhum momento, ele considera o impacto das classes sobre a cidadania. Marshall considera a classe social necessária e útil. O que para ele está em discussão é em quais condições a pobreza pode ser aceitável. Pobreza entendida como a situação daquele que, por falta de reserva econômica, deve trabalhar duramente. Contudo, a indigência, entendida como a situação em que uma família carece do mínimo para viver decentemente, não seria aceitável. Portanto, alguma escala de pobreza não guardaria contradição com os princípios de direitos iguais da cidadania. Lembramos que os direitos civis seriam até indispensáveis para a economia competitiva de mercado.

Em suma, a cidadania teria provocado um efeito integrador ou, pelo menos, foi um elemento importante no processo de integração na Inglaterra. Segundo Marshall, a cidadania "exige um elo de natureza diferente, um sentimento direto de participação numa comunidade baseado numa lealdade a 
uma civilização que é um patrimônio comum" (Marshall, 1967, p. 84). Já no século XVIII, a Inglaterra assistiu não só ao nascimento dos direitos civis modernos, como também da consciência nacional moderna. Todavia, para seus protagonistas não estava de todo claro o quanto os direitos civis e políticos significariam em termos de se evitar conflitos e violência (Marshall, 1967, p. 85).

Para o autor, a igualdade humana teria se realizado no pertencimento a uma comunidade cívica, o estado-nação, no qual os deveres e direitos referidos por Alfred Marshall teriam se potencializado além do simples dever de cavalheiro, disseminando-se no compartilhamento de uma vida civilizada, o que incluiria também um corpo de direitos cuja validade existiria, desde que não invadisse a liberdade do mercado competitivo.

Retomando a idéia da consciência da interdependência da sociedade, questão colocada por Reis (2000), a percepção das elites sobre a pobreza inclui a percepção da sociedade como algo integrado. Esta idéia é fundamental aqui porque colabora na compreensão de uma idéia implícita no texto de Marshall, a percepção das elites acerca da desigualdade como algo que lhes afeta, no sentido de afetar seu bem-viver.

\section{O significado desta discussão no Brasil}

Além da grande importância de T. H. Marshall, reconhecida no Brasil, em relação às conseqüências de um percurso diferente da seqüência histórica inglesa, existe outro aspecto cujo valor investigativo é bastante atual no que se refere ao Brasil. Retomando as duas idéias discutidas aqui, a meu ver, implícitas no trabalho de Marshall, primeiro, que haveria uma rationale das classes dominantes inglesas em relação às desigualdades e, segundo, que também haveria por parte delas uma compreensão da interdependência da sociedade, como se colocaria estas questões no Brasil?

O tema das elites e da pobreza no Brasil, sua convivência histórica e a ausência de uma rationale fazem mais sentido quando se toma como referência uma situação histórica específica e se pensa comparativamente. É recente a preocupação com a pobreza por parte das elites brasileiras, ela se inicia na década de noventa do século vinte (Reis, 2000). 
Sonia Rocha (2005) atribui o surgimento do tema da pobreza, como uma preocupação de toda a sociedade, como resultado do sucesso da estabilização econômica em 1994. Por outro lado, o Banco Mundial, em fins da década de 1980, já colocava em sua agenda, para a América Latina e países periféricos, a questão da pobreza e da desigualdade como matéria prioritária. Schwartzman (2004) vê como tema dominante hoje no Brasil a exclusão social e a pobreza. Este teria tomado o lugar do que há cerca de vinte a trinta anos preocupava os cientistas sociais brasileiros, as questões referentes ao desenvolvimento econômico, à participação política, à democracia e à mobilidade social.

Por que as elites brasileiras sempre tiveram facilidade em tolerar a pobreza? Tomando como referência o artigo citado de Reis (2000) faltaria a elas a noção de interdependência na sociedade. Creio que, para a autora, trata-se da idéia sociológica de integração, tanto no sentido de compartilhar interesses comuns quanto no sentido de percepção de integração na divisão do trabalho, ou, simplesmente, de uma fraca percepção do papel dos trabalhadores na sustentação da ordem social. No contexto da discussão, estaria ausente a noção de responsabilidade social entre as elites. Ao mesmo tempo elas demonstram grande sensibilidade aos problemas da pobreza e da desigualdade, conforme as palavras da autora:

outras respostas do "survey" sugerem com alguma clareza que a ameaça da desigualdade pesa sobretudo como uma ameaça à manutenção da ordem e da segurança pessoal. É sobretudo a problemática da segurança e da manutenção da ordem nas grandes cidades que parece assustar as elites (Reis, 2000, p. 49).

Haveria, historicamente, alguma situação em que as elites brasileiras não tiveram outra opção senão a de negociar e transigir? Seria prematuro ler a situação estudada por Reis, na qual a questão da segurança é mencionada como a principal motivação da atenção das elites em relação aos pobres, como uma explicação para a recente preocupação com a pobreza e a desigualdade?

Retornando à referência do caso inglês, poderíamos considerar que falta no Brasil a idéia de estado-nação? É preciso considerar que os ingleses estavam construindo o mundo para eles viverem e a sociedade para si e seus descendentes, com o mesmo espírito que construíam a ciência, a tecnologia. Nesse projeto, estava incluída a preocupação com a convivência com a desi- 
gualdade de maneira a não afetar seu bem-viver, seja por razões sanitárias, demográficas, econômicas, humanitárias, estéticas ou pragmáticas. Portanto, se aquele projeto falhasse eles não pensavam em construí-lo em outro lugar. Entre as elites já haviam sido construídos alguns consensos. E, ainda que não tivessem total clareza sobre o que significaria historicamente a regulamentação dos conflitos através da ampliação dos direitos civis, como já foi mencionado, mesmo assim é provável que estivessem criando um cálculo do padrão de vida civilizada. Nesse cálculo, mais ou menos claro ou mais ou menos difuso, tinham idéia sobre o grau de pobreza com o qual estariam dispostos a conviver sem ameaçar a vida civilizada.

No Brasil, haveria por parte das elites uma idéia de construir um país considerando que se não funcionasse não teriam outras opções? As elites no Brasil sempre pensaram na possibilidade de, diante de uma crise, retirarem suas famílias e seus investimentos para colocá-los em outro lugar. Por sua vez, se considerarmos o projeto nacional do período populista, esse tampouco apresentava um caráter universalista. Consentido pelo arranjo entre o estado, as elites agrárias e as elites comprometidas com o processo de industrialização, o projeto nacional-populista conviveu perfeitamente com a pobreza urbana e, especialmente, a rural, sustentadas no próprio caráter da aliança que o compunha. ${ }^{3}$ Assim, o projeto populista enquanto experiência de reconhecimento, ainda que limitado, não foi capaz de inspirar um sentimento de pertencimento a uma comunidade cívica duradoura e, menos ainda, algo que apontasse para a expansão do processo de inclusão social.

Nessa reflexão, o caso do Brasil, suas diferenças em relação ao caso clássico inglês, não são vistas como desvios, mas como um problema a ser objeto de investigação. Nessa perspectiva de análise incluem-se as especificidades sustentadas pelas instituições, pelas escolhas das elites, pelo papel do Estado e pelos padrões da cultura cívica existentes em determinados momentos. A consideração da importância da seqüência histórica inglesa dos direitos civis, políticos e sociais não deve ser tomada como uma prescrição, mas

3 A visão organicista, que era o substrato de uma idéia corporativa de nação, sustentava-se na noção de desigualdade entendida como funções diferentes num organismo equilibrado. Este orquestrado pelo Estado como um poder regulador da sociedade e ao mesmo tempo com a função de corrigir os exageros das injustiças sociais. Esta concepção, que segundo Schwartzman (2004, p. 24-25) permaneceu inalterada, está por ele sintetizada de maneira exemplar. 
como um recurso de explicação. Essa seqüencia inglesa, segundo Carvalho (1995), reforçou a convicção democrática. Com os direitos civis vinham as liberdades garantidas por um poder Judiciário, independente do Executivo e com uma tradição de neutralidade, registrada tanto por Moore como por Marshall. As instituições desenvolvidas nessa fase eram os Tribunais de Justiça que serviam de intermediação política e se reforçavam na medida em que exerciam suas funções. Com base no exercício dessas liberdades e das instituições correspondentes, ampliaram-se os direitos políticos e com eles o desenvolvimento dos partidos e a consolidação do Legislativo. Através destes sancionaram-se os direitos sociais que o Executivo punha em prática. Portanto, as liberdades civis constituíram-se na base de todo o processo (Carvalho, 1995).

No caso do Brasil, a inclusão dos direitos sociais, no período varguista, deu-se num contexto de ausência de direitos políticos e civis, restritos aos trabalhadores urbanos com carteira assinada, cuja profissão o estado reconhecia oficialmente. O conceito de cidadania regulada cunhado por Santos (1977) é, pois, a expressão da não universalidade dos direitos, específico do caso brasileiro, diferente da seqüência descrita por Marshall ao analisar o caso inglês. Esse processo de reconhecimento dos direitos sociais vindo do estado, direcionado a um determinado setor da sociedade, em um contexto de ausência de direitos civis e políticos repete-se durante a ditadura Médici, quando os direitos sociais foram ampliados aos trabalhadores rurais. Contudo, no Brasil, salvo entre os especialistas, existem resistências para se reconhecer a importância do modelo de Marshall para o estudo da cidadania. Isto se dá, em parte, por considerá-lo etnocêntrico, em parte, porque a idéia de cidadania está impregnada de ativismo político e, ainda, por não compreender a relação entre a seqüência de direitos marshalliana e a democracia.

Caberia então perguntar: só o medo seria capaz de empurrar as elites à compreensão do que Reis assinala como consciência da integração do sistema social? A tolerância com a existência de graus de pobreza (cerca de 53 a 62 milhões de pessoas abaixo da linha da pobreza) incompatíveis com o padrão de modernidade e democratização do país terá alguma explicação recente ademais das condições herdadas do corporativismo, do paternalismo e da subserviência históricas? 
A convivência da riqueza e da pobreza nos países periféricos tem uma explicação estrutural na abordagem do geógrafo Milton Santos, para quem essa convivência é muito mais dramática nas metrópoles dos países periféricos. A existência da pobreza seria o produto da convivência e da interdependência de dois circuitos do capital, inferior e superior, em uma relação complexa que perpetua a exclusão social. Em termos muito genéricos, pode-se dizer que esses circuitos se diferenciaram em um conjunto de categorias, entre as quais destacam-se as diferenças de tecnologia, de organização do trabalho e do consumo. Portanto, a convivência da pobreza com a riqueza no mesmo espaço não seria um acidente, mas um fenômeno histórico que se agrava com a urbanização acelerada dos países subdesenvolvidos, que só seria alterado com uma política de estado. Com tais considerações se quer dizer que a convivência no mesmo espaço de pobres e ricos, nesses países, seria exigência do próprio modelo de organização e da tecnologia (Santos, 2005). Nesse sentido, a convivência entre os economicamente muito desiguais tenderia a se agravar na medida em que não houvesse uma política de estado efetiva. Sendo a pobreza e a exclusão uma espécie de lógica que se perpetua, poder-se-ia esperar um aumento da consciência das elites dada a aceleração desse fenômeno nas metrópoles dos países periféricos? Haveria possibilidade de uma mudança da cultura das elites ou do padrão da própria cultura política, de modo que de um momento a outro se passasse a incluir essa preocupação?

Encerraria esta discussão com a consideração de uma situação de convivência no mesmo espaço de dois extremos de pobreza e riqueza que ocupou lugar na imprensa como um fenômeno nada natural, melhor dizendo, com algum espanto. A manchete foi assim como se segue: "Favela tem que trabalhar 1 mês para comprar 2 jeans da Daslu". O que aqui interessa é que tendo o fato aparecido como manchete de jornal pode significar alguma surpresa com uma ordem não-natural, isto é, produzida pelos homens. O segundo aspecto a nos remeter ao saudoso geógrafo é que segundo a notícia: "Tamanha desigualdade é separada apenas por um muro", a favela Coliseu separa-se por um muro do Shopping mais luxuoso de São Paulo. Esta seria uma espécie de caricatura da convivência dos dois circuitos do capital, ocorrida a partir da inauguração da cadeia de lojas Daslu, os mais pobres e os mais ricos passaram a que conviver espacialmente numa espécie de situação de risco não programado, para as elites (Jornal Terra, 3/6/2005). 
A idéia de risco não programado sugere elites incautas, conceito incompatível com a história do país. Por outro lado, essa idéia adquire mais sentido quando se compara com a maneira como as elites inglesas resolveram o problema da convivência com a desigualdade. Em outras palavras, em que sentido o trabalho de T. H. Marshall ainda pode esclarecer a questão do desenvolvimento da cidadania no Brasil? Quais seriam os pontos mais relevantes para uma discussão sobre a efetivação da cidadania no Brasil de acordo com a teoria da cidadania de T. H. Marshall? Em primeiro lugar, a análise de Marshall contém elementos com capacidade de fazer estranhar as condições históricas nas quais se desenvolveram os direitos no Brasil, seja em relação a sua seqüência, seja na postura das elites ao lidar com as desigualdades e com os direitos universais. Em segundo, a idéia de estado-nação seria um fator diferenciador no que diz respeito, ao auto-entendimento da sociedade como interdependente, advindo daí sua capacidade de levar as elites ao debate sobre qual seria o grau de desigualdade tolerável. Isto se se considera que, no debate sobre a desigualdade e a pobreza, os reformistas tenham desempenhado um papel relevante na Inglaterra. Quer dizer, a idéia de nação incluiria a formação de consensos sobre a auto-imagem compartilhada por muitos que, em uma situação de desigualdade extrema, chamada pelos ingleses de indigência, se constituiria em um ponto crítico para a persistência de si mesma. Finalizando, o que daqui se depreende é que não bastaria uma situação de perigo potencial para empurrar as elites ao cálculo do grau de desigualdade compatível com seu bem-viver, seria necessário ainda que elas compreendessem a situação como arriscada para seus projetos.

Seria essa a única alternativa capaz de mudar o padrão das elites de adoção de soluções não-universalistas nos processos de inclusão social? Até que ponto uma motivação externa como a de fazer parte dos países prósperos e reconhecidamente "civilizados" poderia servir de impulso à mudança dessa tradição das elites brasileiras?

As perguntas parecem mais freqüentes que as respostas nas considerações traçadas neste artigo. Talvez, porque o debate público acerca da desigualdade no Brasil, especificamente no que se refere à posição das elites diante do problema, ainda demande um envolvimento maior da sociedade. Em linhas finais, não havia nenhuma pretensão conclusiva, mas sim o desejo de se explicitar questões, a meu ver profícuas, acerca da postura das elites brasileiras em relação às desigualdades. 


\section{Referências}

BENDIX, H. Construção nacional e cidadania. São Paulo: Edusp, 1996.

CARVAlHO, J. M. Cidadania: tipos e percursos. Estudos Históricos, n. 18, p. $337-$ $359,1995$.

. Pontos e bordados. Belo Horizonte: Ed. Ufmg, 1998.

HABERMAS, J. O estado-nação europeu frente aos desafios da globalização. Novos Estudos Cebrap, n. 43, nov. 1995, p. 87-101.

HIMMELFARB, Gertrude. The idea of poverty. Londres: Faber and Faber, 1984.

_. Poverty and compassion. New York: Alfred A. Knopf, 1991.

MANN, M. Ruling class strategies and citizenship. Sociology, v. 21, n. 3, p. 339-359, 1987.

MARSHALL, T. H. Cidadania, classe social e status. Rio de Janeiro: Zahar, 1967.

; BOTOMORE, T. Ciudadanía y clase social. Madrid: Alianza, 1998.

REIS, Elisa P. Percepções da elite sobre pobreza e desigualdade. São Paulo. RBCS, v. 15, n. 42, p. 144-152, 2000.

ROCHA. S. Pobreza no Brasil. Rio de Janeiro: Ed. FGV, 2005.

SANTOS, Wanderley G. Cidadania e justiça. Rio de Janeiro: Campus, 1977.

SANTOS, Milton. O espaço dividido. São Paulo: Ed. Edusp, 2005.

SARTORI, G. A política. Brasília: Ed. UnB, 1997.

SCHWARTZMAN, S. As causas da pobreza. Rio de Janeiro: FGV, 2004.

TURNER, Bryan. Outline of a theory of citizenship. Sociology, v. 24, n. 2, p. 33-61, 1990.

Recebido em 24 de janeiro de 2006 e aprovado em 4 de fevereiro de 2006 